\title{
Precipitous fall of the forced expiratory volume
}

\author{
PETER HOWARD AND TREVOR W. ASTIN \\ From the Department of Medicine, University of Sheffield
}

Two patients are described who showed a precipitous loss of forced expiratory volume from normal to low levels within a few years. They did not have bronchial asthma and we suggest that this pattern of deterioration may occur occasionally in patients before they attend hospital with the symptoms of chronic bronchitis.

Patients attending hospital on account of chronic airways obstruction usually present with breathlessness. Most, at this stage, are found to have a severe reduction of the forced expiratory volume (F.E.V.), but little is known about the nature of the deterioration in ventilatory function in earlier phases of the illness. Two patients are described to show how precipitous this deterioration may be. The observations illustrate that the step-wise drop in function reported in some patients (Howard, 1967) may be sufficiently large to plunge a few individuals from normal levels of ventilatory capacity into severe disability within a few years.

\section{CASE REPORTS}

CASE 1 A.P. was first seen in 1956 at the age of 54 years, giving a 10-year history of early morning cough and winter bronchitis necessitating 1-2 weeks off work annually. Effort dyspnoea of steadily increasing severity had been present for one year. On physical examination the only abnormal signs were found in the respiratory system. Chest expansion was poor, the lung fields were enlarged to percussion, the breath sounds were generally reduced, particularly at the bases, and a few scattered wheezes were audible.

A partial gastrectomy had been performed in 1947, but his previous health had been otherwise good. His father died of bronchitis at the age of 57 years. For seven years before being seen he had been employed as a welder, but had worked at the coal face for 18 years from the age of 15 : he had also had a spell in the Army. He had smoked 25 cigarettes per day until about one year before attending outpatients.

His breathlessness had increased until 1959, when he was forced to give up work. Routine examination revealed an abdominal mass which proved to be an aortic aneurysm. A chest infection followed the resection, which was otherwise uneventful. There was never any evidence of heart failure and he was nक्ष cyanosed. He remained dyspnoeic until the autuma of 1964, when he suffered a severe chest infectio $\vec{b}$ from which he never adequately recovered: the was radiographic evidence of bronchopneumonia He was not seen again before his death in November 1965 , which was said to have been due to acue cor pulmonale. The electrocardiogram was coros sistently normal and the chest film demonstrated enlarged lung fields, suggesting generalized emph sema, and a fine nodulation suggestive of pneume coniosis.

The Table shows the measurements of F.E.V. and forced vital capacity (F.V.C.), and Fig. 1 shows plot of the values against time. The F.E.V. on initial referral to the clinic was normal for his age ang height (predicted value 2.5 litres (Baldwin, Cournan and Richards, 1948)) and considerably higher tham that observed for most of our patients. The sub sequent course was one of a precipitous fall un in 1961, when it levelled out at about 0.5 litre. The F.V.C. also declined, but more slowly than the F.E.V. The sputum was observed to be intermittent? purulent and Streptococcus pneumoniae was isolated on occasions. Microscopic examination did not rever an excess of eosinophils, although specific coun were not made. There was no eosiniphilia in theo peripheral blood. In $19620.25 \mathrm{~g}$. of aminophylline injected intravenously caused a small improvemer in the F.E.V. from 0.3 litre to 0.8 litre and of the F.V.C. from 2.8 litres to 3.0 litres. It was not feft on clinical grounds nor as a result of these investigations that the precipitous fall of the F.E.V. could due to bronchial asthma. The severity of cough, phlegm, and winter chest illnesses did not appear to be any different before, during, or immediately after the steep fall of ventilatory capacity. The breathles: ness, however, increased rapidly.

The total lung volume (T.L.C.) and residual volumie were measured by a closed-circuit helium techniqtre (Gilson and Hugh-Jones, 1949) in 1959 and 1968 The values of T.L.C. were 7.38 litres and 7.81 lites 
respectively, with corresponding residual volumes of $52 \%$ and $56 \%$. Arterial blood withdrawn in 1962 showed a saturation for oxygen of $94.5 \%$ and a carbon dioxide tension of $42 \mathrm{~mm}$. $\mathrm{Hg}$.

CASE 2 J. G. was first seen in 1951 at the age of 47, when he volunteered to take part in a long-term follow-up study of the symptoms of bronchitis. He was entirely symptom-free and considered himself to be in good health. He was still symptom-free in 1956, when measurements of the F.E.V. were begun,

T A B L E

MEASUREMENTS OF F.E.V. AND F.V.C. MADE DURING FOLLOW-UP STUDIES

\begin{tabular}{|c|c|c|}
\hline Date & F.E.V.0.75 & $\underset{\text { (1.) }}{\text { F.C }}$ \\
\hline \multicolumn{3}{|c|}{ Patient A.P. Case 1} \\
\hline $\begin{array}{r}2.5 .57 \\
7.10 .58 \\
30.1 .59 \\
20.3 .62 \\
7.11 .62 \\
20.11 .62 \\
12.2 .63 \\
9.4 .63 \\
4.6 .63 \\
30.7 .63 \\
22.10 .63 \\
14.1 .64 \\
10.3 .64 \\
5.5 .64 \\
12.5 .64 \\
9.6 .64 \\
29.8 .64\end{array}$ & $\begin{array}{l}2.4 \\
1.9 \\
1.2 \\
0.6 \\
0.3 \\
0.9 \\
0.7 \\
0.9 \\
0.8 \\
0.7 \\
0.8 \\
0.5 \\
0.6 \\
0.6 \\
0.5 \\
0.6 \\
0.9\end{array}$ & $\begin{array}{l}3.5 \\
2.8 \\
3.0 \\
2.5 \\
2.8 \\
2.8 \\
2.8 \\
1.9 \\
2.2 \\
2.3 \\
2.3 \\
1.8 \\
2.1 \\
2.0 \\
1.8 \\
1.9 \\
2.4\end{array}$ \\
\hline Predicted $^{1}$ & $2 \cdot 5$ & $3 \cdot 6$ \\
\hline \multicolumn{3}{|c|}{ Patient J.G. Case 2} \\
\hline $\begin{array}{l}1956 \\
1962 \\
1965 \\
1966 \\
1967\end{array}$ & $\begin{array}{l}3.9 \\
3.7 \\
2.5 \\
2.4 \\
1.6\end{array}$ & $\begin{array}{l}5 \cdot 0 \\
4 \cdot 6 \\
4 \cdot 4 \\
3 \cdot 8 \\
3 \cdot 2\end{array}$ \\
\hline Predicted & $3 \cdot 0$ & $3 \cdot 8$ \\
\hline
\end{tabular}

${ }^{1}$ The predicted values were calculated according to the formulae of Baldwin, Cournand, and Richards (1948). and remained so until 1966, when he experienced his first attack of winter bronchitis. In the past 18 months he has had two further chest illnesses necessitating time off work, but he has denied a productive cough between attacks. A progressive effort dyspnoea has developed during this period, and he is now limited to walking at his own pace on the level. There is no hypertension nor recognizable cardiac defect.

The past health has been excellent, with no major illness. $\mathrm{He}$ is a non-smoker, and worked as a turner for 20 years before becoming a tool-room foreman. The Table shows the measurements of F.E.V. and F.V.C. and Fig. 1 a plot of the values against time. The F.E.V. fell in two steps, one between 1962 and 1965 and the other between 1966 and 1967. The 1967 figure has been checked on three occasions during a period of one month. The F.V.C. has also been falling steadily, but the decline began after that for the F.E.V. and even now is still $89 \%$ of his predicted value (Baldwin et al., 1948). He was investigated in some detail in November 1967. The T.L.C. measured by the closed-circuit helium technique was normal at $6,478 \mathrm{ml}$. The F.V.C. at this point was $3 \cdot 2$ litres, making the residual volume $51 \%$ of the total lung volume. The specific airways conductance measured by the whole body plethysmograph (DuBois, Botelho, and Comroe, 1956) was $0.07 \mathrm{sec}^{-1} \mathrm{~cm}^{-\mathrm{H}_{2} \mathrm{O}^{-1}}$ (normal values in this laboratory: $0 \cdot 16-0 \cdot 31 \mathrm{sec}^{-1} \mathrm{~cm} . \mathrm{H}_{2} \mathrm{O}^{-1}$ ). An arterial blood gave values for $\mathrm{Po}_{2}$ of $75 \mathrm{~mm}$. $\mathrm{Hg}$, for $\mathrm{PCO}_{2}$ of $35 \mathrm{~mm}$. $\mathrm{Hg}$ and $\mathrm{SaO}_{2} 93 \cdot 5 \%$. The $\mathrm{A}-\mathrm{aDO}_{2}$ was raised $(36 \mathrm{~mm}$. $\mathrm{Hg})$ and the three-compartment analysis of lung distribution (Penman and Howard, 1966) gave values for the alveolar dead space fraction (Fup.v) of $36.1 \%$, for the alveolar blood shunt fraction (Fuv.p) $6.3 \%$, and for the effective fraction (Fvp) $63.6 \%$. Our normal values for these compartments in the sitting position are: Fup.v 25\%, Fuv.p $3 \%$, and Fvp $72 \%$. The static recoil pressures of the lung $\left(P_{s t}\right)$ were measured by the method of MilicEmili, Mead, Turner, and Glauser (1964). Figure 2
FIG. 1. The decline of the F.E.V.0.75 and F.V.C. in (left) Case 1 and (right) Case 2. The arrows indicate acute chest illnesses for which antibiotics were given. $O p=$ operation. $P l=$ pleurisy.
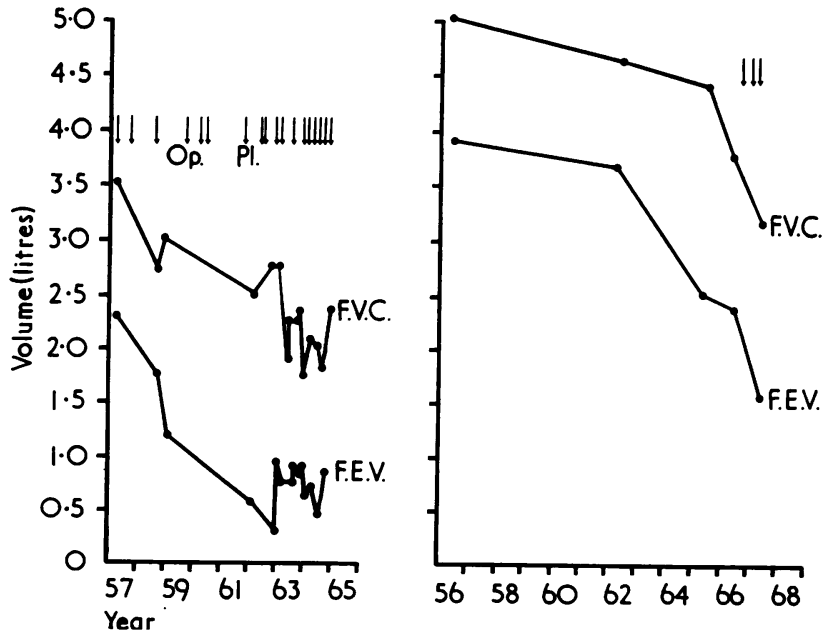
shows a plot of the values of $\mathbf{P}_{\mathbf{g t}}$ at various levels of the vital capacity which, judging by the work of Mead, Turner, Macklem, and Little (1967), would appear normal. Dynamic compliance at a respiratory frequency of $11 / \mathrm{min}$. was also normal at $0 \cdot 181 . / \mathrm{cm}$. $\mathrm{H}_{2} \mathrm{O}$. Inhaled isoprenaline improved the F.E.V. from 1.6 litres to 1.8 litres and the F.V.C. from 3.2 litres to 3.6 litres. At the time of study he could not produce any sputum. Thus, in summary, this patient shows a marked reduction of F.E.V. minimally affected by isoprenaline, a decrease of airways conductance, normal overall elastic properties of the lung as reflected in the measurements of dynamic compliance and static recoil pressure, and evidence of ventilation-perfusion inequality.

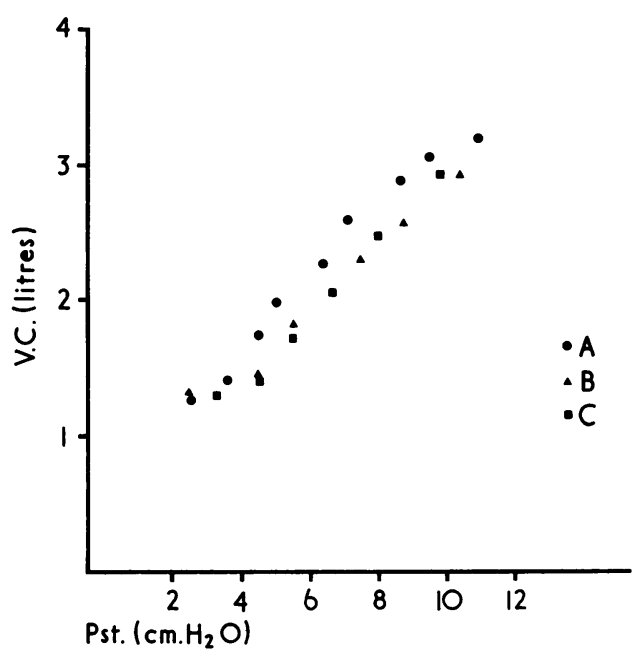

FIG. 2. The relationship between the static-recoil pressure of the lung $\left(P_{s t}\right)$ and vital capacity (V.C.). Three series of measurements were made $(A, B$, and $C)$ under the same conditions.

His chest radiographs in 1965 showed a normal heart and lung fields except for some peaking of the right diaphragm and a pleural adhesion to the sixth rib anteriorly.

\section{DISCUSSION}

Hospital patients with chronic bronchitis are a selected group of those who have chronic airways obstruction. The F.E.V. is usually much reduced from normal levels on first presentation, in our experience to about 1.0 litre. Most patients give a history of many years' productive cough and winter illnesses before the onset of breathlessness, but in some patients the previous history is shorter and breathlessness might be the initial complaint. Hospital patients probably include the more severely disabled, but little is known about them before they achieve this level of disability.
There is considerable variation in the rate of $\overrightarrow{\vec{F}}$ deterioration of the F.E.V., but in some patientso it may be no greater than that reported for nor-으 mal populations even when the F.E.V. reaches $\frac{\overline{\bar{s}}}{\overline{2}}$ low levels (1.0 litre). Presumably, therefore, in these $\mathbb{\varnothing}$ latter individuals the F.E.V. must have been fall-o ing at a greater rate in previous phases of the $e^{\infty}$ disease. The decline of the F.E.V. occurs in two. ways - by a steady deterioration and by sudden $\overrightarrow{\vec{H}}$ drops (Howard, 1967). These cases are presented ${ }_{\sigma}^{\omega}$ because they illustrate how rapidly ventilatory function as measured by the F.E.V. may deter-i iorate, and that one type of disease preceding. severe disability may involve a precipitous decline of function from normal levels. In the first patient $\mathrm{N}$ the sudden drop of function occurred after manyo years of productive cough, winter illnesses, heavy smoking, and an occupational hazard. There wasc no indication as to why the sudden deterioration $\frac{}{<}$ should occur at that moment. The acute chest $\vec{\circ}$ illness recorded before the precipitous fall in 1958 seemed to be similar to his many previous winter illnesses. The importance of the relation of bron-o chial infection (as manifested by symptoms of phlegm and acute chest illnesses) to the decline of the F.E.V. has been questioned. In a study by the Medical Research Council (1966) on early chronic $\cong$ bronchitis in which the F.E.V.1.0 was greater than $\overrightarrow{\overrightarrow{0}}$ 1.46 litres, chemoprophylaxis or treatment of $\exists$ acute exacerbations as they occurred had no effect on the decline of the F.E.V. Howard (1967), in a follow-up study of more severely disabled individuals, could find no more than a weak correla-o tion between the decline of the F.E.V. and the $x$ number of acute chest illnesses per year. Cigarettes smoking has been repeatedly associated with lowerF.E.V. levels and also with an increased rate of decline of the F.E.V. (Higgins and Oldham, 1962 Fletcher, 1968). This patient had stopped smoking by the time the precipitous decline occurred. If these factors are important to the decline of the F.E.V. then it must be presumed that some other factor combined to achieve the precipitous deter ioration in this patient.

In the second patient, the fall of F.E.V. was equally dramatic and for the most part asympto? matic. He did not have bronchial asthma, there was no smoking history and no occupationa hazard. Thus the commonly recognized causes of obstructed airways were not in evidence. Mead et al. (1967) and Macklem and Mead (1967) have्ष pointed out that expired flow is dependent upon? the elastic recoil of the lung and the mechanica $B$ properties of the larger airways. Obstruction of large number of smaller bronchioles in a normab dog lung was observed to have little effect upory 
the F.E.V. In our patient the overall elasticity of the lung was normal: the fall in F.E.V. was probably due to a disturbance in the larger airways and was associated with a moderate decrease in airways conductance. Disease of the small airways $(<2 \mathrm{~mm}$. in diameter) is considered to be an important cause of ventilation-perfusion abnormality and this was clearly abnormal. There is evidence of disorder in both small and large airways, but it is not clear from these studies whether the progress of disease in these different parts of the bronchial tree can develop independently.

About 200 patients regularly attend the bronchitis clinic, but only 25 had an F.E.V. of $2 \cdot 25$ litres or greater when first seen. The first patient was drawn from this group of 25 . The second patient was taken from a long-term follow-up study of 290 industrial workers, most of whom were initially healthy individuals. This man was the only one to show such a precipitous fall of ventilatory function although many others had step-wise losses of less severity. It is difficult to assess from these figures how frequently a precipitous loss of F.E.V. might occur in an urban community, but it is suggested that this is one type of deterioration that occurs in patients with obstructed airways before they attend hospital.

\section{REFERENCES}

Baldwin, E. de F., Cournand, A., and Richards, D. W., Jr. (1948) Pulmonary insufficiency I. Physiological classification, clinica methods of analysis. Standard values in normal subjects. Medicine (Baltimore), 27, 243.

DuBois, A. B., Botelho, S. Y., and Comroe, J. H., Jr. (1956). A new method of measuring airway resistance in man using a body plethysmograph: values in normal subjects and in patients with respiratory disease. J. clin. Invest., 35, 327.

Fletcher, C. M. (1968). Bronchial infection and reactivity in chronic bronchitis. J. roy. Coll. Phycns Lond., 2, 183.

Gilson, J. C., and Hugh-Jones, P. (1949). The measurement of the total lung volume and breathing capacity. Clin. Sci., 7, 185.

Higgins, I. T. T., and Oldham, P. D. (1962). Ventilatory capacity in miners: A five-year follow up study. Brit. J. industr. Med., 19, 65.

Howard, P. (1967). Evolution of the ventilatory capacity in chronic bronchitis. Brit. med. J., 3, 392.

Macklem, P. T., and Mead, J. (1967). Resistance of central and peripheral airways measured by a retrograde catheter. J. appl. Physiol., 22, 395.

Mead, J., Turner, J. M., Macklem, P. T., and Little, J. B. (1967). Significance of the relationship between lung recoil and maximum expiratory flow. Ibid., 22,95 .

Medical Research Council Report (1966). Value of chemoprophylaxis and chemotherapy in early chronic bronchitis. Brit. med. J., 1 , 1317.

Milic-Emili, J., Mead, J., Turner, J. M., and Glauser, E. M. (1964). Improved technique for estimating pleural pressure from esophageal balloons. J. appl. Physiol., 19, 207.

Penman, R. W. B., and Howard, P. (1966). Distribution of pulmonary ventilation and blood flow in normal subjects and patients with chronic bronchitis. Clin. Sci., 30, 63. 